\title{
Encruzilhadas do Ensino: reflexões sobre as ações afirmativas de acesso à universidade pública brasileira
}

\section{At the Crossroads of Teaching: reflections on affirmative action concerning the access to Brazilian public universities}

\author{
Alexandre Mossmann ${ }^{1}$, Marcos Rafael de Oliveira Barbosa ${ }^{2}$, Liana Netto Dolci ${ }^{3}$, Daniele Pioli dos \\ Santos ${ }^{4}$, Gabriela Verrastro Brack ${ }^{5}$, Amadeu de Oliveira Weinmann ${ }^{6}$ \\ 1 Graduando em Psicologia. Universidade Federal do Rio Grande do Sul (UFRGS). Brasil. E-mail: xan.mossmann@gmail.com \\ 2 Psicólogo. Universidade Federal do Rio Grande do Sul (UFRGS). Brasil. E-mail: rafael_psicoufrgs@hotmail.com \\ 3 Graduanda em Psicologia. Universidade Federal do Rio Grande do Sul (UFRGS). Brasil. E-mail: lianadolci@hotmail.com \\ 4 Graduanda em Psicologia. Universidade Federal do Rio Grande do Sul (UFRGS). Brasil. E-mail: piolidaniele@gmail.com \\ 5 Graduanda em Psicologia. Universidade Federal do Rio Grande do Sul (UFRGS). Brasil. E-mail: gabriela.brack@hotmail.com \\ 6 Professor. Programa de Pós Graduação em Psicanálise: Clínica e Cultura / Universidade Federal do Rio Grande do Sul (UFRGS), \\ Brasil. E tutor do Programa de Educação Tutorial de Psicologia da Universidade Federal do Rio Grande do Sul (UFRGS), Brasil. \\ E-mail: weinmann.amadeu@gmail.com
}

Recebido em: 02/08/2016 | Aprovado em: 04/03/2017

DOI: 10.12957/interag.2017.24939

\section{Resumo}

Encruzilhadas do Ensino é o primeiro projeto do PET Psicologia UFRGS a se dedicar ao trabalho com estudantes de uma escola pública de ensino médio. A iniciativa surgiu com a gradual alteração no perfil do grupo, transformado pelo crescimento do número de bolsistas ingressantes nessa universidade por meio da política de ações afirmativas. A fim de contribuir para a expansão de tal política pública e incrementar a discussão sobre o acesso à universidade com estudantes da rede pública de ensino, o grupo procurou aproximar da universidade estudantes que nem mesmo tinham o ensino superior como um objetivo em suas vidas. Como resultado de suas intervenções, o grupo viu o projeto funcionando como um dispositivo subjetivante, lançando os/as estudantes participantes na busca por novos horizontes.

Palavras-chave: Ações Afirmativas; Universidade; Subjetivação; Programa de Educação Tutorial.

\begin{abstract}
At the Crossroads of Teaching is the first project of UFRGS Psychology TEP (Tutorial Education Program) that is dedicated to working with students from a public high school. The initiative emerged with the gradual alteration on the group profile, which changed after the growth of students with a scholarship at the university due to the implementation of affirmative action policies. In order to contribute to the expansion of this policy and to develop the discussion regarding the access to the university with students from public schools, the group tried to bring closer to the university, students that not even had higher education as a life objective. As a result of those interventions, the group saw the project working as a subjectifying device, moving the participants towards the pursuit of new horizons.
\end{abstract}

Keywords: Affirmative Actions; University; Subjectivity; Tutorial Education Program.

Área temática: Educação.

Linha de extensão: Direitos individuais e coletivos, Grupos sociais vulneráveis; Jovens e adultos. 


\section{Introdução}

O Grupo PET (Programa de Educação Tutorial) Psicologia da UFRGS é composto por 12 estudantes da graduação em Psicologia de diferentes semestres e por um tutor, docente do mesmo curso. Os/as integrantes partem de diversas filiações teóricas, o que enriquece e diversifica o leque de atividades do grupo. Seu objetivo é desenvolver a aprendizagem tutorial e o trabalho coletivo, contribuindo para qualificar a formação em Psicologia com experiências que promovam a capacidade crítica, a autoria e o compromisso social.

O grupo é responsável pela organização e planejamento de diversas atividades que ocorrem paralelamente, sendo o Encruzilhadas do Ensino o primeiro projeto a se dedicar a trabalhar com estudantes em uma escola de ensino médio pública. A proposta do Encruzilhadas surgiu no primeiro semestre de 2013, quando o grupo, ao refletir sobre os resultados da atividade realizada no UFRGS Portas Abertas (evento anual dessa universidade, que abre suas portas para que estudantes secundaristas conheçam os cursos que ela oferece) do curso de Psicologia daquele ano, constatou que a referente ação era quase que exclusivamente usufruída por alunos/as oriundos/as de escolas particulares de Porto Alegre e região metropolitana. Essa constatação despertou no grupo o anseio de expandir a relação da universidade com os estudantes do ensino médio de escolas públicas.

O trabalho com alunos/as do ensino médio do Colégio Estadual Padre Rambo, de Porto Alegre, surge como uma proposta de desnaturalizar o perfil do/a universitário/a. Percebemos que o perfil dominante deste/a aluno/a, no imaginário social brasileiro, afeta de maneira significativa o contorno no qual os/as estudantes do ensino médio inserem suas perspectivas de vida. O que chamamos de imaginário social configura-se como o enunciado de uma prática discursiva embasada nas relações de saberpoder historicamente constituídas em nossa sociedade e que, ainda hoje, atravessam as práticas de si, os modos como os sujeitos conduzem suas vidas. "A universidade é para quem tem dinheiro e para quem é branco" (frase proferida por um aluno da escola): este 
enunciado define o regime de verdade hegemônico no laço social contemporâneo, o qual orienta determinados processos de subjetivação:

Os processos de subjetivação [...] podem ser compreendidos a partir da análise da maneira como cada indivíduo se relaciona com o regime de verdades próprio a cada período, ou seja, a forma como o conjunto de regras que define cada sociedade é experienciado em cada trajetória de vida. ${ }^{1}$

Mediante um recorte étnico e econômico, as ações afirmativas surgem com o intuito de possibilitar o acesso de minorias historicamente excluídas a lugares estratégicos, como a universidade pública. Essa é uma mudança significativa na política educacional brasileira, a qual foi conquistada com grande esforço pelos movimentos sociais. Embora a consideremos um grande avanço, ainda é grande o número de críticas que essa recebe, inclusive daqueles/as que supostamente seriam beneficiados por ela. O principal argumento é de que tal prática é inconstitucional ou, pior, que dividirá ainda mais a sociedade brasileira. Nessa linha de raciocínio, a partir do esforço individual qualquer trajeto é possível. Esse é um discurso meritocrático e neoliberal, que também nega a existência de racismo no Brasil. Quase sempre os mesmos exemplos são utilizados para sustentar essa lógica: Barack Obama e Joaquim Barbosa, dois homens negros que nasceram pobres e conseguiram vencer na vida, sem benefícios de qualquer tipo. Em um primeiro momento, encontramos falas como essas no trabalho com a escola. Com a perspectiva de desconstruir verdades historicamente construídas e que claramente favorecem determinado grupo social, buscamos problematizar esses discursos propondo aos/às estudantes uma reflexão acerca de suas histórias de vida e de suas famílias, de seus planos e suas dificuldades para torná-los realidade. 


\section{Cenário socioeconômico e familiar}

Os/as alunos/as que acompanhamos no Colégio Estadual Padre Rambo - a grande maioria oriunda do bairro Lomba do Pinheiro e da Vila São José, localizados na periferia da cidade - sentiam necessidade de trabalhar desde cedo em suas vidas, restando apenas o turno da noite como possibilidade de continuar os estudos. Em seus relatos, percebíamos que essa era uma dificuldade transgeracional. Seus pais, seus avós e demais ancestrais tiveram ainda menos condições de seguir a educação formal, sendo o diploma do ensino médio um título que poucos/as daquele meio social podiam ostentar. Portanto, finalizar o quanto antes os estudos e se dedicar exclusivamente ao trabalho, como fizeram seus ancestrais, era praticamente a única opção que vislumbravam. $\mathrm{O}$ estabelecimento de ensino também não tinha como prática falar das formas de acesso à universidade, o que contribuía para o desconhecimento dos/as alunos/as sobre as possibilidades desse ingresso. Essas condições acompanham a triste história brasileira de exclusão de muitos em benefício de poucos. O que lhes era oferecido pela cultura em que estavam imersos/as, que se constituía como regime de verdade e se exercia como processo de subjetivação, era sempre o mesmo lugar à margem da sociedade.

Nesse trabalho de desconstrução, propomos um enlace entre a história do Brasil e o que essa implica em suas vidas. $O$ principio da igualdade, previsto na Constituição Federal de 1988, que pressupõe que tratemos os desiguais na medida de suas desigualdades, fundamenta a existência das ações afirmativas. Certamente, a isonomia é um avanço, já que até o surgimento da República, em 1889, os/as negros/as eram proibidos/as de frequentar as escolas. Na Constituição de 1824, por exemplo, era garantido o acesso à escola a todos os cidadãos. Contudo, os/as negros/as não eram considerados/as cidadãos, o que, de maneira indireta, lhes impossibilitava ocupar os espaços formais de aprendizagem. Essa proibição era mais evidente na Resolução Imperial $n^{\circ}$ 382, datada de $1^{\circ}$ de julho de 1854, que determinava: "Art. 35 - Os professores receberão por seus discípulos todos os indivíduos, que, para aprenderem primeiras letras, lhe forem apresentados, exceto os cativos, e os afetados de moléstias contagiosas”.2 
Nos quinhentos e dezesseis anos de história do Brasil, trezentos e oitenta e oito foram de escravidão. Nosso país só está livre dessa ferida há cento e vinte e oito anos. O sangramento ainda não estancou, já que sabemos que os efeitos do racismo e da desigualdade social continuam a reverberar na vida da maior parte dos/as brasileiros/as, com seus efeitos econômicos entrelaçados aos subjetivos. Em 2013, os negros e negras do Brasil - segundo dados do IBGE - tiveram uma renda média de $\mathrm{R} \$ 1.374$, enquanto que a população branca teve um rendimento médio de $\mathrm{R} \$ 2.390$. Segundo o Instituto de Pesquisa Econômica Aplicada (IPEA), essas rendas só irão se equivaler no ano de 2040.3 Nos setores com menor remuneração, a maioria dos trabalhadores é negra. É o caso da agricultura $(60,3 \%)$, da construção civil $(57,9 \%)$ e dos serviços domésticos $(59,1 \%)$. Com relação ao estudo, o percentual de negros/as entre 18 e 24 anos no ensino superior no ano de 2001 era de apenas 10,2\%, enquanto que o percentual de brancos/as era de 39,6\%. Nos últimos dez anos, houve uma mudança significativa, mas ainda insuficiente. O percentual de estudantes negros/as nessa faixa etária passou para $35,8 \%$, enquanto o de jovens brancos passou para 65,7\%. Contudo, a distância entre essas duas populações continua sendo assustadora, configurando-se como um analisador para este trabalho.

Esse é o contexto em que se inserem os/as alunos/as das turmas de ensino médio do Colégio Padre Rambo, com quem o grupo PET Psicologia UFRGS trabalhou no Encruzilhadas do Ensino. Em meio a essas condições históricas e sociais, que fazem parte de sua história de vida e das gerações que os/as antecederam, esses/as alunos/as enfrentam também as mudanças características da adolescência. $O$ período do ensino médio coincide com essa etapa, que pode ser vista como um processo de transformação preparatório para a entrada na vida adulta, pautada principalmente por uma reestruturação das relações sociais e dos modos de compreensão do mundo. Tem início o processo de individuação, de separação do núcleo familiar, de descoberta de limites próprios, de questionamento dos valores e das normas familiares e de adesão aos valores e normas do grupo de amigos. ${ }^{4}$

O cenário social é relevante nessa fase de drásticas mudanças. $\mathrm{Na}$ adolescência, ocorre uma nova revivência do reconhecimento do eu e do outro nas 
relações socioafetivas. Essa revivência está muito ligada aos papéis sociais ligados ao trabalho. A partir desse momento, o indivíduo sofrerá mudanças significativas na esfera corporal, psíquica, relacional e social. ${ }^{5}$ A passagem da infância à adultez vem se dando de novos modos, mediada pelo contexto histórico atual, onde transformações na estrutura e no funcionamento familiar refletem e, ao mesmo tempo, são base para mudanças culturais.

Considerada a unidade básica da interação social, a família modificou-se gradualmente de um modelo hierárquico, no qual o homem encarnava o papel de autoridade e a mulher a figura afetiva, para um modelo de família igualitário, no qual os papéis são cada vez mais simétricos entre as figuras familiares de autoridade e onde os/as filhos/as têm mais espaço e voz nas decisões, numa dinâmica de reciprocidade e equivalência. ${ }^{6}$ Importante lembrar também que a configuração familiar ampliou-se, desprendendo-se da configuração tradicional homem, mulher e filhos/as, para cada vez mais se diversificar, incluindo na concepção atual de família casais homossexuais, uniões consensuais, famílias chefiadas por mulheres (ou monoparentais), famílias reconstituídas, entre outras configurações da contemporaneidade. 4 Nos/as alunos/as do Padre Rambo, percebemos que as questões relativas à organização familiar impactam de outra maneira. $\mathrm{Na}$ contramão do fenômeno social de adolescentização - protelamento da entrada no mundo adulto, em favor de experimentar o "sabor da vida"7,8 -, esses/as jovens sentem mais cedo a necessidade de colaborar com o sustento de sua família ou de se emancipar, sequer considerando ter acesso ao ensino superior. Esses/as adolescentes são demandados/as a um amadurecimento precoce em relação a outros/as jovens, pelas diferenças sócio-históricas que consideramos anteriormente, o que traz outro ponto crucial de nossa análise: o sentido do trabalho para esses/as jovens.

O primeiro emprego traz inúmeras possibilidades, abre um novo período de vida, com novos projetos e planos futuros. Por meio da construção de uma identidade profissional específica, a perspectiva de futuro se afirma através da realização de projetos profissionais, mas distancia o jovem de classe baixa da universidade. Bustos ${ }^{9}$ postula que uma pessoa só consegue se imaginar em papéis que estejam disponíveis no seu meio 
social, de modo que esses jovens, oriundos da periferia de Porto Alegre, têm pouco convívio com pessoas que tenham ensino superior completo, pessoas em quem possam se inspirar e que tragam motivação para buscar a continuação do estudo formal. Dessa forma, é muito difícil que eles consigam se imaginar como estudantes universitários, diminuindo seu leque de possibilidades. Esses estereótipos são reforçados pela sociedade como um todo, nas grandes mídias e na relação com o trabalho, sendo historicamente construídos e aceitos como únicos modos de vida acessíveis aos jovens de baixa renda.

Entendemos que a apropriação do mundo pelo sujeito é mediada por determinadas representações sociais. De acordo com Moscovici10, representações sociais são as afirmações que os indivíduos fazem sobre sua realidade, sendo um produto de determinações sócio-históricas e consistindo no processo de subjetivação do mundo. Representação social também se define como uma atividade mental de reorganização e recriação do real pelos sujeitos. Em outras palavras, elas não consistem em um reflexo do meio em que se vive, mas são uma ativa construção mental do objeto e orientam a ação do sujeito. Os sistemas sociais de significação, ao serem interiorizados pelo indivíduo, ganham um sentido pessoal e assim se individualizam. Dito de outro modo, são subjetivados.

Atualmente, os jovens estão inseridos em um contexto de rápido desenvolvimento tecnológico, no qual a instantaneidade permeia as relações humanas em uma sociedade de hiperconsumo. Dessa forma, esses aspectos exacerbam a exclusão social, tornando os adolescentes alvos do individualismo, além de banalizarem a violência e as condutas ilícitas. Porém, acredita-se que os jovens não são meramente vítimas do sistema, são agentes pensantes de seus próprios destinos. Partindo desse princípio, o trabalho feito junto às turmas do Colégio Padre Rambo possibilitou a reflexão sobre o meio em que esses/as estudantes estavam inseridos e em que medida isso afetava as suas vidas.

A partir dessa visão, trabalhamos com o conceito de empoderamento do sujeito, através do Encruzilhadas do Ensino. Acreditamos que esse empoderamento se deu devido ao processo de subjetivação do qual fizeram parte em sala de aula com o 
grupo do PET, passando pela fala/escuta e pelo olhar do exterior. Também é uma forma de subjetivação e socialização a resistência, ou seja, o fato de os alunos se perceberem como participantes de uma luta contra as formas de dominação atuais (étnica, social, etc.), que permeiam seu meio. ${ }^{11}$

\section{Encruzilhadas como um dispositivo subjetivante}

Nos meses de outubro a dezembro de 2013, o PET Psicologia UFRGS começou a se encontrar quinzenalmente com duas turmas de ensino médio do Colégio Estadual Padre Rambo: a $1 \mathrm{~L}$ e a $2 \mathrm{~K}$, respectivamente do primeiro e segundo ano do ensino médio. Os encontros, que duravam cerca de 50 minutos, eram realizados em parceria com a professora Carol Cezar, titular da disciplina de filosofia. Ao todo, foram realizados oito encontros, nesse período. Cinco desses ocorreram com a turma de segundo ano $2 \mathrm{~K}$ e três com a turma de primeiro ano $1 \mathrm{~L}$. Os objetivos que orientaram o desenvolvimento da atividade foram: promover dispositivos para estimular o pensamento crítico em estudantes de ensino médio, disseminar a reflexão acerca de temas relacionados com a cidadania na atualidade e esclarecer as possibilidades de acesso à universidade.

Em 2014, o grupo deu continuidade ao projeto, acompanhando os/as alunos/as da turma $3 \mathrm{~K}$, oriundos/as da turma $2 \mathrm{~K}$. Nesse momento, a proposta foi dar ênfase ao importante ciclo da vida dos/as estudantes que se encerrava - o ensino médio e se lançar a pensar os sonhos e planos para os próximos anos. Para isso, buscamos conversar sobre os cursos e profissões com os quais aqueles/as jovens se identificavam, questionando-os sobre como gostariam de estar no futuro e instigando-os a amadurecerem seus sonhos. Aqui, o dispositivo entra como uma possibilidade, um gerador de diferença que transforma a realidade. ${ }^{12}$ As inserções do grupo, valorizadas pela presença de um ex-aluno daquela escola, mostraram que os/as estudantes de ensino público também têm aspirações, mas que, em sua realidade socioeconômica, por vezes não existe espaço - nem sequer esperança - para viabilizar esses desejos. A possibilidade 
de escuta dos/as estudantes como um dispositivo abriu muitos caminhos, deu voz e os/as empoderou, dando vazão a desejos que, por não terem reconhecimento ou espelhamento nos outros à sua volta, não eram legitimados. ${ }^{13}$

Nos encontros de 2014, foram utilizados diferentes dispositivos que serviram de disparadores para a conversa. Entre esses, técnicas do Psicodrama, como jogos dramáticos e trabalhos em grupos, nos quais os estudantes tinham que criar um personagem que os representasse no futuro. $\mathrm{O}$ uso do referencial psicodramático se deu pela potência deste em utilizar a realidade social dos envolvidos como material de trabalho, colocando os indivíduos como pertencentes a um meio e não como seres isolados, investigando vínculos e colocando-os em movimento na busca de atribuição de sentidos para sua condição. ${ }^{14}$ Além disso, foram realizadas rodas de conversa onde compartilhamos com os/as estudantes como foi a trajetória de cada integrante do PET Psicologia UFRGS até a universidade. Com o intuito de aproximá-los/as do ambiente universitário, organizamos uma visita ao Instituto de Psicologia da UFRGS. Nesta, tivemos a parceria de outros grupos PETs e demais alunos da graduação em Psicologia, os quais dialogaram com os/as alunos/as do Colégio Padre Rambo acerca das peculiaridades dos seus respectivos cursos. Nessa ocasião, também contamos com a presença de um palestrante do curso pré-vestibular popular Resgate, responsável por difundir entre os/as alunos/as esse importante dispositivo.

Em 2015, continuamos a realizar o Encruzilhadas do Ensino com outras turmas do Colégio Padre Rambo. A partir das experiências e resultados alcançados ao longo do projeto, sentimos a necessidade de expandir as atividades e, no segundo semestre de 2015, iniciamos as Oficinas Itinerantes, dispositivo que leva a outros estabelecimentos de ensino médio a discussão sobre as ações afirmativas e o acesso à universidade. 


\section{Considerações finais}

A intervenção do PET Psicologia UFRGS no Colégio Padre Rambo, longe de impor um ideal a ser seguido - o imperativo: estude! -, buscou preservar as singularidades dos/as alunos/as, tendo como real objetivo desmistificar o imaginário de que ingressar em uma universidade e realizar um curso superior são tarefas impossíveis a eles/as. A intenção desse trabalho foi criar possibilidades para que os/as estudantes pudessem perceber que, caso fosse seu desejo realizar um curso superior, há, sim, possibilidade para isso, pois a universidade - principalmente a pública, em tempos de ações afirmativas não é um lugar apenas para as elites, mas também abre espaço para alunos/as oriundos/as da escola pública. Sentimos o despertar dos/as alunos/as para realidades desconhecidas. Percebemos que, graças ao uso de dispositivos que variaram de acordo com o momento e as necessidades que as turmas expressavam, foram geradas inovações e possibilidades antes impensáveis na vida de muitos/as que tiveram a oportunidade de participar desse projeto.

A experiência obtida com o Encruzilhadas do Ensino nos propiciou compreender melhor as representações sociais dos/as estudantes do ensino médio de escolas públicas, especificamente no que diz respeito ao acesso à universidade. $\mathrm{O}$ alto nível da reflexão dos/as alunos/as do Colégio Padre Rambo acerca de suas potencialidades como adolescentes, estudantes e cidadãos mostra que nosso objetivo de promover o desenvolvimento do pensamento crítico foi alcançado. Além disso, os/as alunos/as expandiram seu poder de autoanálise e ampliaram a busca de novos objetivos para o futuro, a partir de nossas discussões sobre seu espaço no mundo - profissional ou não.

\section{Contribuição de cada autor:}

Alexandre Mossmann, Marcos Rafael de Oliveira Barbosa, Liana Netto Dolci, Daniele Pioli dos Santos e Gabriela Verrastro Brack coordenaram o projeto Encruzilhadas do 
Ensino e redigiram este artigo. Amadeu de Oliveira Weinmann orientou a redação do artigo.

\section{Referências}

1. NARDI, H.; YATES, D. Transformações contemporâneas do trabalho e processos de subjetivação. In: Psicologia em estudo, Maringá, v. 10, n. 1, p. 95-103, 2005.

2. REIS, F. Cultura escrita e a escravidão brasileira: algumas práticas e seu significado no século XIX. In: BARREIRA, L.] CARVALHO, M. (Orgs.). II Seminário sobre leitura, escola, 2003. história, Disponível em: http://alb.com.br/arquivo-morto/edicoes_anteriores/anais15/seminarios08.htm. Acesso em 20 de abril de 2015.

3. RODRIGUES, L. População negra supera a branca neste ano, mas renda só se equipara em 2040. Folha de São Paulo [online], edição de 13 de agosto de 2008. Disponível em: http://www1.folha.uol.com.br/mercado/2008/05/401394-populacaonegra-supera-branca-neste-ano-mas-renda-so-se-equipara-em-2040.shtml?mobile. Acesso em 20 de abril de 2015 .

4. PRATTA, E. SANTOS, M. Família e adolescência: a influência do contexto familiar no desenvolvimento psicológico de seus membros. In: Psicologia em estudo, Maringá, v. 12, n. 2, p. 247-256, mai./ago., 2007.

5. FONSECA, J. Psicodrama da loucura: correlação entre Buber e Moreno. São Paulo: Ágora, 1980.

6. STENGEL, M. O exercício da autoridade em famílias com filhos adolescentes. In: Psicologia em revista, v. 17, n. 3, p. 502-552, dez., 2011.

7. MOTA, C.』 ROCHA, M. Adolescência e jovem adultícia: crescimento pessoal, separação-individuação e o jogo das relações. In: Psicologia: teoria e pesquisa, Brasília, v. 28, n. 3, p. 357-366, jul./set., 2012. 
8. SAVIETTO, B. Juventude e família na contemporaneidade: um desamparo sem fim? In: Gerais: revista interinstitucional de psicologia, São Paulo, v. 5, n. 1, p. 23-35, jan./jun., 2012.

9. BUSTOS, D. Asas e raízes. In: HOLMES, P.】 KARP, M. $\square$ WATSON, M. O Psicodrama após Moreno: inovações na teoria e na prática. São Paulo: Ágora, 1998. p. 91-106.

10. SALLES, L. A representação social do adolescente e da adolescência: um estudo em escolas públicas. In: Cadernos de pesquisa, São Paulo, n. 94, p. 25-33, ago., 1995.

11. MANSANO, S. Sujeito, subjetividade e modos de subjetivação na contemporaneidade. In: Revista de psicologia da UNESP, Assis, v. 8, n. 2, p. 110-117, 2009.

12. BAREMBLITT, G. Compêndio de Análise Institucional e outras correntes: teoria e prática. Belo Horizonte: Instituto Félix Guattari, 2002.

13. BARTHES, R. O óbvio e o obtuso. Lisboa: Edições 70, 1990.

14. ROJAS-BERMÚDEZ, J. Introdução ao Psicodrama. São Paulo: Ed. Mestre Jou, 1977. 